This article was downloaded by: [University of Arizona]

On: 04 September 2012, At: 14:32

Publisher: Routledge

Informa Ltd Registered in England and Wales Registered Number: 1072954 Registered office: Mortimer House, 37-41 Mortimer Street, London W1T 3J H, UK

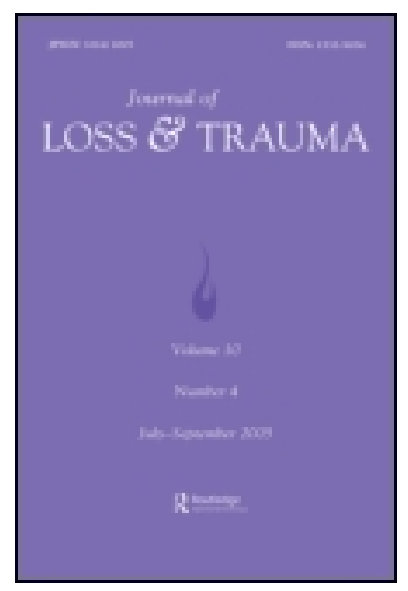

J ournal of Loss and Trauma: International Perspectives on Stress \& Coping

Publication details, including instructions for authors and subscription information:

http:// www. tandfonline.com/loi/ upil20

\title{
Mediating Grief: Postmortem Ritualization After Child Death
}

J oanne Cacciatore ${ }^{a} \&$ Melissa Flint ${ }^{b}$

${ }^{a}$ School of Social Work, Arizona State University, Phoenix, Arizona, USA

${ }^{b}$ College of Heath Sciences Clinical Psychology Program, Midwestern University, Glendale, Arizona, USA

Accepted author version posted online: $14 \mathrm{~J}$ un 2011. Version of record first published: 06 Feb 2012

To cite this article: J oanne Cacciatore \& Melissa Flint (2012): Mediating Grief: Postmortem Ritualization After Child Death, J ournal of Loss and Trauma: International Perspectives on Stress $\&$ Coping, 17:2, 158-172

To link to this article: http:// dx.doi.org/ 10.1080/ 15325024.2011.595299

\section{PLEASE SCROLL DOWN FOR ARTICLE}

Full terms and conditions of use: http://www.tandfonline.com/page/terms-and-conditions

This article may be used for research, teaching, and private study purposes. Any substantial or systematic reproduction, redistribution, reselling, loan, sub-licensing, systematic supply, or distribution in any form to anyone is expressly forbidden.

The publisher does not give any warranty express or implied or make any representation that the contents will be complete or accurate or up to date. The accuracy of any instructions, formulae, and drug doses should be independently verified with primary sources. The publisher shall not be liable for any loss, actions, claims, proceedings, demand, or costs or damages whatsoever or howsoever caused arising directly or indirectly in connection with or arising out of the use of this material. 


\title{
Mediating Grief: Postmortem Ritualization After Child Death
}

\author{
JOANNE CACCIATORE \\ School of Social Work, Arizona State University, Phoenix, Arizona, USA \\ MELISSA FLINT \\ College of Heath Sciences Clinical Psychology Program, Midwestern University, \\ Glendale, Arizona, USA
}

\begin{abstract}
The purpose of this study is to better understand the benefits of ritualization for bereaved parents and the factors that influence ritualization. Through phenomenological analyses of 19 in-depth interviews with bereaved parents, the results of this study reveal that bereaved parents engage in ritual to (a) maintain continuing bonds with their child, (b) belp them cope by offering them a sense of control, and (c) provide a means toward posttraumatic growth by bonoring and memorializing their child. These factors, in turn, appear to mediate grief through meaning reconstruction in the aftermath of the child's life and death within the context of social and cultural influences. Implications for providers are discussed.
\end{abstract}

Ritual has been defined as "any activity—sacred or secular, public or private, formal or informal, traditional or newly created ... that includes the symbolic expression of a combination of emotions, thoughts, and/or spiritual beliefs of the participant(s) and that has special meaning" (Castle \& Phillips, 2003, p. 43). There are emotional, as well as evolutionary, benefits to ritualization that confer benefit to individuals and groups. Kastenbaum (2004) describes ritual as acts performed by people who are unified as a group, through established patterns and collective expressions, involving a knowing of something that others don't while addressing the most difficult aspects of the human experience. "Rituals invoke the past for control over the future" (p. 98).

Received 21 April 2011; accepted 3 June 2011.

Address correspondence to Joanne Cacciatore, School of Social Work, Arizona State University, Phoenix, AZ 85004, USA. E-mail: dr_joanne@me.com 
Reeves (2011) notes that rituals are "out of the ordinary activities" that act as a bridge, crossing "thresholds from one status to another" (p. 409).

Death rituals transform and mediate grief, facilitate meaning-seeking, and help mourners maintain a symbolic connection to the dead. Painful emotions (Parkes, 1996) can be effectively negotiated, perhaps even channeled, through ritual after death. For bereaved parents, there is often a physical and psychological imperative to remain bound to the child (Cacciatore, 2010). They maintain "an ongoing connection ...through a sacred symbolic space in which the children now reside ... transition then becomes a matter of finding a new psychosocial existence that has no formally recognized social status" (Romanoff \& Terenzio, 1998, p. 707).

\section{A HISTORICULTURAL EXAMINATION OF RITUAL}

Across cultures and throughout history, human civilizations have developed, embraced, rejected, and restructured rituals around the two most common experiences: birth and death. In particular, rituals have been used universally as a way of coping with death (Beder, 2002), providing an opportunity to express emotions and offering mourners an "antidote to powerlessness" (Miller, 1999). Death rites and rituals were not born of modernity. Neanderthal rituals for the dead date back nearly 50,000 years to burial sites where archaeologists discovered tools, ornamental shells, and even food left for loved ones. Ancient civilizations including the Romans, Egyptians, and Greeks also engaged in sophisticated ritualization of the dead (Lensing, 2001). In ancient Finland, babies born dead would be buried under or near the house, in proximal coexistence with the family. During this period, "no funeral industry existed ... and family members, friends, and neighbors were responsible for" the burial of the dead (Laderman, 1996, p. 9).

Deritualization in ancient Greece was an attempt to limit the power of women, whose role was to lament and otherwise preside over ritual mourning: the state “considered mourning women's lament dangerous to the women themselves and often classified these women as mad, though perhaps only as a way of preventing them from consolidating the power of expression that grief afforded" (Kanter, 2002, p. 1). However, it wasn't until the 18th century that "clergymen ordered the dead to be buried in the churchyard ... death became frightening” in Europe (Vaisanen, 1999, p. 146). The pattern for most Protestants who died in the antebellum urban setting contained the three fundamental elements also found in the rural setting: cosmetic preparation at home, transportation to the gravesite, and internment or entombment in a designated place.

In the United States, during the first half of the 19th century, socioeconomic status affected death rituals. The only time egalitarianism was apparent in urbanized death was at times when great epidemics amassed 
corpses. Otherwise "the children of the poor were not covered by the umbrella of religion, ritual, and conscience" (Kastenbaum, 2004, p. 217). Throughout much of history, divisions of economic and social class had a significant influence on the disposition and ritualization of the dead as "funerals for the wealthy were guarded; yet those of the poor were easily raided" (Sapolsky, 1997, p. 118).

After World War I, hegemonic, economic forces emerged from local and national organizations: Professionals and experts took "their position over the dead," and corpses were subsumed by the opportunistic "nature of the capitalist urban marketplace... into the American way of death" (Laderman, 1996, p. 10). Gorer (1965) asserted that this was the beginning of the end of traditional mourning rituals. Death moved away from being an intimate occasion whereby mourners were at ease with their dead and engaged in potent, approbatory rituals affirming grief and communal mourning rituals. The sense of control during the mourning period and the simplicity of death (Laderman, 1996) were lost in its institutionalization. Aries (1975) notes other factors associated with the interdiction of mourning. Most interestingly, "there is a modern "need for happiness" that emphasizes the "moral duty and the social obligation to contribute to the collective happiness by avoiding any cause for sadness ... by by appearing to be always happy, even if in the depths of despair"' (as cited in Layne, 2003, p. 66). The ritualistic expressions of mourning women-and certainly more recently men-are often incongruent with this ideology. If the language of "feminine grief has been represented as hysterical, masculine grief has scarcely been represented at all" (Kanter, 2002, p. 2). Thus, these responses are often seen pathologized in the medical literature from the late 20th century (Rothaupt \& Becker, 2007; Kanter, 2002). Kastenbaum (2004) agrees: "Deathing" and birthing, he says, have been largely medicalized, with most people being born and dying in institutions.

In a post-war United States, ritualizing through monument is a centerpiece of coping. "Those involved in designing, funding, and building twentieth century war memorials" are exercising their moral duty to remember (Layne, 2003, p. 220). These rituals of collective grief have become more public since the tragedy of September 11, 2001, and have "move[d] ritual into the public sphere and extend the community of support beyond the individual" (Beder, 2002, p. 402). In ritualistic acts of commemoration, community members write letters, leave flowers, erect walls and statues and buildings, and post photographs of the dead. Internet memorializing and virtual graveyards are increasing in response to the Web community's need for public acknowledgment.

\section{BEREAVED PARENTS AND RITUALIZATION}

According to Neimeyer (2001), the constructivist model informs recent shifts in bereavement hegemony. Of particular relevance to this study are the 
trends toward idiographic approaches that challenge the hegemony of stage-based approaches, the growing body of qualitative bereavement data, identity and meaning reconstruction shifting views away from the medicalization of bereavement, and narrative mourning models. In particular, an individual's cognitive narrative is often disrupted when faced with traumatic loss (Neimeyer, 2005/2006). Neimeyer (2004) describes the processing of these narratives as organized "micronarratives of everyday life into macro-narratives that [guide] our performance on the stage of the social world" (pp. 53-54). The radical changes that ensue following traumatic death force bereaved persons to reorganize their narrative, even in the face of suffering (Neimeyer, 2005/2006). This is often done within the social prescriptions of an individual's culture.

Walter (1991) asserts that death is "highly problematic for the modern individual but not at all for modern society," a conclusion he says results in "the lack of ritual surrounding [death] today" (p. 307). In Western culture, as the media is "obsessed with death" there exists a paradox wherein individuals are unable to "talk about their own personal grief" (Walter, 1991, p. 295). For the most part, the modern Western world continues to "repress death and its symbolism" in much the same way as the Victorians repressed sexuality (May, 1969, p. 106). In his book Love and Will, Rollo May (1969) says:

\begin{abstract}
Death is obscene, unmentionable, pornographic...death is not to be talked of in front of the children, nor talked about at all if we can help it. We dress death up in grotesquely colorful caskets in the same way Victorian women camouflaged their bodies ... we throw flowers on the casket to make death smell better... we act as though the deceased had somehow not died; and we preach a psychoreligious gospel that says the less grief the better. (p. 105)
\end{abstract}

There is some residual resistance to ritualizing a dead child "culturally, where some find it morbid and unhealthy, and some clinicians are reluctant to recognize its value" (Jones, 2002, p. 70). In other cases, health care and agency administrators often have a "why bother" attitude toward the ritual (Jones, 2002). This ambivalence translates to other means of ritualizing the deaths of babies and children, such as recent laws in various states preventing roadside memorials after motor vehicle accidents (Sharp, 2005). Western culture, in general, fails to provide families with rituals and other "established means by which to remember babies who died before they became a part of society" (Cote-Arsenault, 2003, p. 35). Walter (1991) notes that the bereaved "often are isolated and may well report being treated as lepers" (p. 301). Thus, they often seek companionship with like others as a source of support, and often this is within the context of a support group (Walter, 1991). Indeed, there are "powerful internal and external forces that prevent truth from 
surfacing" and societal expectations can "reinforce shame," making mourners "more likely to hide" (Richman, 2006, p. 641).

While there are differing definitions about the concept of ritual in the literature, for the purpose of this study a very broad definition of ritual is utilized. Ritual is defined as "a specific behavior or activity which gives symbolic expression to certain feelings and thoughts of the actor(s) individually or as a group. It may be a habitually repetitive behavior or a one-time occurrence" (Rando, 1985, p. 236). This study explores how and why bereaved parents ritualize; examines the genesis of ritualization behavior, which includes farewell behaviors identified by Reeves (2011) such as holding the deceased child during or soon after death; explores factors that influence or discourage beginning and/or ongoing ritualization; and offers suggestions for clinicians and practitioners who work with bereaved families.

\section{METHODOLOGY}

\section{Participants and Procedures}

This study used a phenomenological approach, qualitatively describing the subject's lived experience. Primary data were collected through in-person, audiotaped interviews with 19 different subjects, all conducted by the primary researcher. The subjects were recruited through two local self-help support groups for bereaved parents. Both support groups are open format groups and relationship-specific; that is, they are for bereaved parents solely, though the children died at various ages and from various causes. All data were collected using 11 open-ended questions that guided the interview. Question 1 inquired about the exceptionality and individuality of the circumstances surrounding the death of the child(ren). Questions 2-5 focused on actualizing the rituals. This section included questions about funeral and/or memorial services, farewell behaviors (seeing/holding the child after death), roles in planning for service(s), and ways in which the subject chose to ritualize (e.g., details of ritual, private or public). Questions 6-8 explored the personal meaning attributed to the ritual, including perceived benefits and adverse effects emerging from the ritualization process. Finally, Questions 9-11 focused on social support, including the responses and roles of others in remembering the child. Additionally, Question 11 prompted reflection about how others have influenced the way parents remember and memorialize their child.

\section{Data Analysis}

Data from the qualitative interviews were first transcribed verbatim and then coded into thematic categories, or psychological meaning units (Giorgi, 1985), including contact (holding/seeing child after death), funeral and 
memorial services, purpose, benefits, negative aspects, responses of others, those involved, influences on how to ritualize, realizations, times of year, public or private, and miscellaneous or other. If a theme was repeated within any one interview, each occurrence was counted separately for purposes of data collection. Data were then thoroughly reviewed and subcategorized into themes that identified and expressed the phenomenologically lived experience of the interviewees. These processes not only allowed the isolation of common ideas but illuminated important perceptions about the meaning of rituals, beginning in the early days following the child's death.

\section{Descriptive Statistics}

Participants included both male and female parents of deceased children; 15 respondents were mothers, and 4 were fathers. The age of the subjects ranged from 28 to 51, with a mean of 36.25 at the time of the interview. There were 15 Caucasian/European Americans (78\%), 1 African American (5.5\%), 1 Native American-Navajo/Hopi (5.5\%), and 1 Asian (5.5\%). Self-identified religious categories included Buddhist $(n=1 ; 5 \%)$, nondenominational Christian $(n=1 ; 5 \%)$, Christian $(n=8 ; 29 \%)$, traditional Navajo $(n=1 ; 5 \%)$, Episcopalian $(n=2 ; 11 \%)$, Catholic $(n=2 ; 11 \%)$; and Lutheran $(n=1 ; 5 \%)$; 3 individuals stated no religious preference (16\%). The socioeconomic status of the participants included 5\% each lower and upper, with the majority $(90 \%)$ falling within the middle socioeconomic strata. The ages of the children at the time of their death ranged from stillbirth to 15 years of age. The nature of death was most often sudden and unexpected, and the time from the death until the interview ranged from 1 year to 18 years.

\section{RESULTS}

Parents reported feeling "compelled" toward farewell behaviors with their child. Some described an intense "yearning" to hold and care for their deceased child. In addition to holding, touching, and rocking, some parents of younger children chose to bathe their child. Two of the 19 participants reported that their children died "in [their] arms," while 11 others saw their child immediately after death. While many parents held $(n=7)$, stroked $(n=1)$, rocked $(n=2)$, and even crawled into bed with $(n=1)$ their child during the postmortem period, one participant in the study reported turning away from the dead child. Farewell behaviors that offered something tangible such as locks of hair, hand- and footprints, and photographs were important to many parents. In particular, parents suffering perinatal death made reference to looking at "every part" of the baby, commenting on how the baby looked and felt, as if to memorize his or her features. Parents were influenced by the way others responded. One parent stated, "I walked 
around with him on my shoulder. I talked to him. Then everyone started coming in. Some looked at me like I was insane for holding him-the older people-like why would you do that?" Even more parents expressed a desire to have someone to guide them during their moments after death. "We stayed with him and just loved him. I wish I held him longer. I wish I had asked to see him longer. I wish I had asked to see him again.... To have spent more time caring for him, bathing him, rocking him. Why didn't I think of these things?" One mother of a 16-year-old boy who died "made the nurses clean him up and I crawled into bed with him for a few hours. I wanted to remember how he felt and looked. Every whisker, every freckle, every part of him."

When asked about regrets, there was an overwhelming response by parents who did not hold their child now wishing that they had $(n=6)$. For those who did hold their child, regrets surrounded the amount of time they were allowed to be with their child, reflecting an overwhelming feeling that they regretted not holding, touching, and being with their child longer $(n=14)$. One mother stated that no matter how long she would have been able to hold her child, "it would have never been enough." Twice, one father reflected that he had only one chance to hold his child "and I turned it down". Another said that as his wife held their child she asked him to do so as well, but he refused because "it hurt too much." Additionally, for those who did hold their child, there were several comments about regret over not holding their child longer. Along similar lines, parents also regretted not spending more time with their child in the moments following death $(n=8)$. Other regrets included not kissing the child, not having more time alone with the child, not bathing him or her, and not rocking or talking to the child. Farewell behaviors and rituals during the acute period seemed to be particularly potent.

Having photographs of their children was a universally important thing to all of the parents who experienced perinatal death and for one of the mothers of an older child who died. Unfortunately, for some, photographs were not taken or offered: "No pictures. I thought a lot about it but my mom said it was morbid." Another mother reflected, "We didn't have a camera or think we needed one. Now I'm so upset we don't have photos.... You build memories on the photos. It's the only real, visual memory because things fade and change." And another said, "I documented his entire life so I felt it was appropriate to document his death."

Parents expressed a range of very similar emotions from feelings of disbelief and shock $(n=5)$ to depersonalization, feeling "out of it," and dissociation from reality $(n=4)$. One noted, "Losing him was like getting hit with a baseball bat." Another stated, "Pieces of me were gone." The anguish was described by a participant who said, "I was yelling and begging her to come back." Parents also used words such as "surreal" ( $n=6$ ) to describe their emotional experience. Other terms reflecting depersonalization were 
mentioned ( $n=5)$ and included "in a daze" and "like watching someone else go through it." Parents with surviving children also described the struggle of deciding whether or not to allow siblings an opportunity to participate in the farewell and other rituals. One mother said her children were "very involved," but two others, both who did not include siblings, expressed regret: "I thought it was best for the other children to not see their sibling," and "[my daughter] still begrudges me that [she was] not a part of the experience."

A recurring theme emerged with regards to how the parents were treated by medical staff in the immediate hours after death. Many parents reflected on feeling rushed in their farewells by various members of the hospital and/or funeral home employees $(n=8)$. "For me, I needed to hold and cradle her... there were many people there and I didn't get time alone. I wish I had more time alone with her. I felt kind of rushed." Another stated, "The nurses came in and tried to demand that I leave because the police needed to take the body as evidence. I told them that I would leave when I was ready to leave him." One parent noted that "we were at the absolute worst time in our lives and they wouldn't listen to us." A single participant described the funeral director as a "used car salesman."

Out of the 19 respondents, 10 had a funeral and/or memorial service for their child, and parents described feeling "overwhelmed" and "horrible." For those parents who were, for whatever reason, uninvolved in the funeral/ memorial, several wished they had been more "in control" and "involved" $(n=3)$. One parent said this was one of the "last mothering things" she could do for her child and, for this reason, was very important. A number of respondents reported that they felt a need to "take control" over the service to ensure the tribute to their child was meaningful $(n=10)$. Many parents placed letters to their child, photographs, stuffed toys, and other personal items in the casket. Additionally, respondents indicated that they did not know what to do and wished that someone "in authority" would have guided them in their decision-making process. Postmortem ritualization was experienced as a remarkably important expression of mourning for these parents. There were 51 comments about personal mementos that parents kept, ranging from hospital wristbands, cards, and flowers to handprints/footprints and locks of hair. In an effort to remain connected with their child, one family saved the cell phone bill documenting their time from arrival at the hospital to departure. Universally, having these tangible artifacts was identified by the parents as positive; often, however, others, in particular family members, viewed it as negative.

Parents also seemed to use rituals as a means of immortality so that their child could "live on" and be remembered, both privately and publicly. There were 95 comments outlining specific activities participants undertook to memorialize their children. Most of the parents experienced a public to private trajectory. That is, during the first few months following the child's death, 
the ritualization tended toward being more public and involved surviving children, parents, relatives, and friends. Over time, however, rituals tended to become more private, at least in part due to questioning or criticizing from others. One father reflected that his family had become "much more private because of how society views her-it's easier for me and our family to have more private memorializing. It avoids invalidating responses. Most everyone doesn't acknowledge [her] and I don't want her memory tarnished." Parents seemed to gravitate, at some point, away from those they felt "don't understand their grief," seeking support from like others. Some parents noted that they discovered new opportunities to ritualize from other bereaved parents in support groups $(n=11)$ and felt the groups normalized their feelings.

While the more traditional rituals were often discussed in the stories of participants, many more of the participants engaged in new, less traditional rituals. Overall, nontraditional rituals were mentioned more than 50 times and included creative acts of memorialization such as "Build-A-Bears," scrapbooks, memorial Web sites, commemorative jewelry, auto window stickers, personalized Christmas cards and ornaments, balloon releases, volunteering and participating in random acts of kindness, and tattoos. Parents in this study reflected on the importance of helping others in a multitude of different ways that may not, at first glance, seem like an actual ritual. For example, attending a support group felt, to some, like a ritualistic act that benefited them at first. However, as time passed attended groups became a way to "give back" to other families who were suffering the same loss as they had $(n=12)$. The use of their personal stories to help other families and, ultimately, to give them "hope" was a recurrent theme. Additionally, other families engaged in acts of altruism, including purchasing gifts on holidays for a less fortunate child. One mother shared, "After I do an act of kindness, I feel closer to him and a sense of relief from the intensity of the grief [that] comes over me."

Every participant in the study stated that rituals were profoundly important to them, reducible into three main categories represented as (a) continued bonds with the child who died, (b) coping, and (c) honoring and memorializing. Despite the importance of ritual in the lived experiences of the participants, there were some perceived negative aspects related to the responses of others. While two respondents stated that they did not experience discouraging feedback, most of the others in the sample conveyed less than supportive responses, often from family members. In total, there were 51 disaffirming responses, such as the suggestion that parents should just "move on" and assertions that "a mother was no longer a mother if her only child had died." While some participants interpreted these negative comments as intentionally hurtful, intended to interrupt their mourning rituals, others felt more empathy: "They didn't know what to do, so they did nothing." Additionally, for some the omission of acknowledgment appeared equally as hurtful as suggestions they stop acknowledging the child after 
an arbitrary period of time (usually following the first holiday or first birthday). "They don't know if they should or shouldn't talk about it. The fact that people don't know what to do or worse suggest I shouldn't feel pain or grief." This did seem to affect many parents' level of comfort around ongoing rituals and may be why some became more private. Parents who experienced perinatal death reported more "unsupportive" responses from others.

\section{DISCUSSION}

The results of this study reveal three salient themes that bereaved parents cite as motivation for ritual: (a) Rituals help parents maintain a sense of continuing bonds with their child; (b) they help them cope by offering a sense of control and power; and (c) they provide a means toward posttraumatic growth through the opportunity to honor and memorialize the child. These factors, in turn, appear to mediate grief through meaning reconstruction in the aftermath of the child's life and death within the context of social and cultural influences.

The enduring psychological presence and physical absence after child death incite high ambiguity and thus high levels of stress for bereaved parents (Boss, 1999; Cacciatore, DeFrain, \& Jones, 2008). The sense of continuing bonds that is born of rituals, as described by parents in this study, seems to reaffirm a type of psychological proximity wherein the deceased continues to be recognized as a beloved family member. Bereaved parents often experience a sense of vulnerability — and shattered world assumptions—after the untimely death of a child (Rubin, Malkinson, \& Witztum, 2003; Green, 2000; Janoff-Bulman, 1992), leaving them feeling helpless and out of control (Cote-Arsenault, 2003). Rituals also seem to mitigate that sense of powerlessness, giving bereaved parents control over their very personal and painful losses.

Parents in this study, consistent with constructivist theory, seemed to use rituals to reorganize, reorient, and construct a new micro-narrative that fits in the social context of the macro-narrative, during both acute and later phases of mourning. Many parents are, indeed, influenced to participate in ritual through social venues such as support groups and communion with other bereaved parents (Umphrey \& Cacciatore, 2011). Here they are able to re-create the child's biographical sketch (Walter, 1996). However, they may also be influenced away from ritual by others who do not understand how they feel or why they feel compelled to continue bonds in this way. As a result of feedback from others, many parents in this study chose to move their mourning ritual from the public to the private, citing others' intolerance of their enduring grief as the reason. These findings support Walter's (1991) assertion that death is not forbidden; rather, it is hidden because of the "intense personal pain, so intense that others are unwilling to share it" (p. 306). 
Yet, mourning rituals are a language of emotional expression that may aid bereaved parents to maintain a sense of control, reconstruct meaning, and develop an infrastructure to cope with their loss. Whatever the ritual itself is, it must be meaningful to bereaved parents, allowing them to add new meaning to the experience and/or reconstruct prior meanings in light of the profound circumstances in which they now find themselves. "The use of symbols, such as tangible objects, words, or movements, creates individualized meaning for each participant, ultimately facilitating their journey through grief" (Kobler, Limbo, \& Kavanaugh, 2007, p. 291). The participants in this study seemed to appreciate both traditional and nontraditional rituals, perhaps a clarion call for clinicians to expand their definition and understanding of ritual to include symbol, story, and ceremony (Combs \& Freedman, 1990).

\section{Implications for Practice}

While a broad definition of rituals includes group identification, collective expressions, shared stories and secrets, and a sense of control (Kastenbaum, 2004), it is critical for clinicians to expand the parameters for rituals and seek creative ways in which to engage clients experiencing child death, as follows.

- Metaphor and symbol: something that stands for something else and that can evolve in meaning over time, and the use of words as representations of experience and associations.

- Stories: The substrates within which several discrete symbols are embedded and interrelated.

- Ceremony: new patterns, actions, and intentional experiences that are symbolic. Even psychotherapy itself can be a ceremony, emphasizing exploration, awareness, and transformation through the use of symbols and stories (Combs \& Freedman, 1990, p. 14; Reeves, 2011). Certainly, the parents in this study seemed to experience varying degrees of posttraumatic growth by honoring their child through day-to-day kindness toward others and volunteerism.

As the results of this study suggest, parents are influenced by others when it comes to ritual. Providers play an important role in facilitating death rituals from the acute crisis to long-term mental health services. Importantly, there are profound implications that result from failing to use ritual therapeutically in the final moments before and after death. Encouraging death rituals early in the grief process facilitates the capturing of important memories and mementos and may help parents by minimizing regret. Parents often look to providers for guidance or advice, wondering if, for example, holding a 5-year-old who died is culturally appropriate. Kobler et al. (2007) reflect on the importance of initiating a discussion about ritual while considering the 
timing of the ritual as a "critical element" for staff as they care for bereaved families. "The reality of time constraints, patient acuity, and staff shortages require a precise, focused method of learning what is important and what is meaningful to another person," the entire basis of a therapeutic relationship (p. 293). To this end, the concept of guided participation is of particular salience.

Workman (2001) cites guided participation as one way to approach bereaved families about rituals. Just as their telling of the story is important to the bereaved, so too are the gentle information-seeking questions of supportive providers. In the asking of questions, however, there must be an acknowledgment that providers will be required to develop innovative approaches to common therapeutic protocols or policies (Kobler et al., 2007). Comprehensive training on how to deal with the bereaved individual or family within the very specific context of perinatal death is crucial, particularly given the sparse opportunities for rituals, such as memento photographs, with a baby they never brought home (Cacciatore, 2009; Cacciatore, Schnebly, \& Froen, 2009).

Both administrators and providers are in a unique position to advocate for comprehensive continuing education for staff, changing the infrastructure for handling child deaths, if necessary. Bereavement programs, including mental health agencies, should focus on effective and culturally competent communication skills for all staff, including those who work in intake and pastoral care, interns and residents, and even nonclinical staff. The opportunity to co-create ritual throughout the therapeutic experience allows for transformation of even the typical into a meaning-making experience (Kobler et al., 2007). Additionally, parents may continue to benefit from ritual as a way to reconstruct both identity and meaning and to foster continuing bonds despite the number of years that have passed since the child's death. Mental health providers are in a unique position to mindfully shepherd parents through this process, even years later.

\section{Limitations}

As with any qualitative study, there are limitations to the generalizability of the data because each narrative reflects a very personal story, unique to each individual or couple. Although the essence of the lived experience of each story is unique, shared perceptions and themes were clear within the narratives. The low number of participants and minimal variability in socioeconomic status, education, and ethnic representation also compromise generalizability. Additionally, all participants were involved in a support group at the time of the interview, and thus results may not be extrapolated to bereaved parents who have never attended a support group. Despite these limitations, there is much to be learned from these data. A phenomenological history is built on each individual story, of which 19 are presented in this study. 


\section{CONCLUSION}

There is a need for clinicians and academics to expand their definition, understanding, and practice of ritual to include stories and metaphors, symbols, and ceremonies (Combs \& Freedman, 1990). Well-trained providers can work within community and family systems to facilitate culturally sensitive rituals that help grieving parents, siblings, and grandparents cope. These rituals can be traditional or nontraditional, formal, or ceremonial acts or procedures that transform the banality of the everyday from the ordinary to the sacred. Rituals help the bereaved regain some sense of control of their very intimate process of grieving, and they are intended to be deeply felt by the mourners and others. These rituals compel others to experience and share the suffering of the grieving family "because of their essentially kinesthetic materiality and their particular embodiment of grief" (Scott, 1991, p. 779). Indeed, the "passage from life to death" and from death to life "has long inspired rituals worldwide... as a hedge against terror and despair" (Kastenbaum, 2004, p. 99).

\section{REFERENCES}

Aries, P. (1975). Images of man and death (J. Lloyd, Trans.). Cambridge, MA: Harvard University Press.

Beder, J. (2002). Mourning the unfound: How we can help. Families in Society, 83, 400-403.

Boss, P. (1999). Ambiguous loss: Learning to live with unresolved grief. Cambridge, MA: Harvard University Press.

Cacciatore, J. (2009). Appropriate bereavement practice after the death of a Native American child. Families in Society, 90, 46-50.

Cacciatore, J. (2010). Unique stories of women and their families after the death of a baby. Journal of Healthcare Social Work, 49, 134-148.

Cacciatore, J., DeFrain, J., \& Jones, K. (2008). Boundary ambiguity and the death of a child. Marriage and Family Review, 44, 439-454.

Cacciatore, J., Schnebly, S., \& Froen, F. (2009). The effects of social support on maternal anxiety and depression after the death of a child. Health and Social Care in the Community, 17, 167-176.

Castle, J., \& Phillips, W. L. (2003). Grief rituals: Aspects that facilitate adjustment to bereavement. Journal of Loss \& Trauma, 8, 41-71.

Combs, G., \& Freedman, J. (1990). Symbol, Story, and Ceremony: Using metaphor in individual and family therapy. New York, NY: Norton.

Cote-Arsenault, D. (2003). Weaving babies lost in pregnancy into the fabric of the family. Journal of Family Nursing, 9, 23-37.

Giorgi, A. (1985). Phenomenology and psychological research. Pittsburgh, PA: Duquesne University Press.

Gorer, G. (1965). Death, grief and mourning in contemporary Britain. London, England: Cresset Press. 
Green, B. L. (2000). Traumatic loss: Conceptual and empirical links between trauma and bereavement. Journal of Personal and Interpersonal Loss, 5, $1-17$.

Janoff-Bulman, R. (1992). Shattered Assumptions: Toward a New Psychology of Trauma. New York, NY: Free Press.

Jones, B. (2002). Good grief: A medical illustrator's view of bereavement photography. Journal of Audiovisual Media in Medicine, 25, 69-70.

Kanter, J. (2002). Hopeful sentences: Gender and mourning language in two contemporary narratives. Women and Language, 25, 1-8.

Kastenbaum, R. (2004). On our way: The final passage through life and death. Berkeley: University of California Press.

Kobler, K., Limbo, R., \& Kavanaugh, K. (2007). Meaningful moments: The use of ritual in perinatal and pediatric death. American Journal of Maternal/Child Nursing, 32, 288-295.

Laderman, G. (1996). The sacred remains: American attitudes toward death, 1799-1883. New Haven, CT: Yale University Press.

Layne, L. L. (2003). Motherbood lost: A feminist account of pregnancy loss in America. London, England: Routledge.

Lensing, V. (2001). Grief support: The role of funeral service. Journal of Loss \& Trauma, 6, 45-63.

May, R. (1969). Love and Will. New York, NY: Norton.

Miller, S. (1999). Finding hope when a child dies: What other cultures can teach us. New York, NY: Simon \& Schuster.

Neimeyer, R. (2001). Reauthoring life narratives: Grief therapy as meaning reconstruction. Israel Journal of Psychiatry and Related Sciences, 38, 171-183.

Neimeyer, R. (2004). Fostering posttraumatic growth: A narrative contribution. Psychological Inquiry, 15, 53-59.

Neimeyer, R. (2005/2006). Complicated grief and the quest for meaning: A constructivist contribution. Omega: Journal of Death and Dying, 52, 37-52.

Parkes, C. (1996). Bereavement: Studies of grief in adult life (3rd ed.). London, England: Routledge.

Rando, T. A. (1985). Creating therapeutic rituals in the psychotherapy of the bereaved. Psychotherapy, 22, 236-240.

Reeves, N. (2011). Death acceptance through ritual. Death Studies, 35, 408-419.

Richman, S. (2006). Finding one's voice: Transforming trauma into autobiographical narrative. Contemporary Psychoanalysis, 42, 639-649.

Romanoff, B. D., \& Terenzio, M. (1998). Rituals and the grieving process. Death Studies, 22, 697-711.

Rothaupt, J., \& Becker, K. (2007). A literature review of Western bereavement theory: From decathecting to continuing bonds. Family Journal, 15, 6-15.

Rubin, S. S., Malkinson, R., \& Witztum, E. (2003). Trauma and bereavement: Conceptual and clinical issues revolving around relationships. Death Studies, 27(8), 667-690.

Sapolsky, R. (1997). The trouble with testosterone. New York, NY: Scribner.

Scott, J. (1991). The evidence of experience. Critical Inquiry, 17, 773-797.

Sharp, D. (2005). Battles over roadside shrines more common. USA Today. Retrieved from http://www.usatoday.com/news/nation/2005-07-11-roadside-memorials_x.htm 
Umphrey, L., \& Cacciatore, J. (2011). Coping with the ultimate deprivation: Narrative themes in a parental bereavement support group. Omega: Journal of Death and Dying, 63, 141-160.

Vaisanen, L. (1999). Family grief and recovery process when a baby dies. Unpublished manuscript.

Walter, T. (1991). Modern death: Taboo or not taboo? Sociology, 25, 293-310.

Walter, T. (1996). A new model of grief: Bereavement and biography. Mortality, $1,7-24$.

Workman, E. (2001). Guiding parents through the death of their infant. Journal of Obstetric, Gynecologic \& Neonatal Nursing, 30, 569-573.

Joanne Cacciatore is an assistant professor in the School of Social Work at Arizona State University. She runs the Graduate Certificate in Trauma and Bereavement Program and works with many students interested in studying the effects of traumatic death. She is also a clinician and has counseled grieving families from around the world since 1996.

Melissa Flint is a clinical psychologist who specializes in geriatrics, child abuse/ trauma, and developmental disabilities. She maintains a private client caseload in the Midwestern University Multispecialty Clinic as well as holding the position of assistant professor in the College of Heath Sciences Clinical Psychology Program. 